\title{
REMOTE LEARNING IMPACTS ON STUDENT WELLBEING
}

\author{
Peter M. Ostafichuk, Mimi Tse, Jacob Power, Carol P. Jaeger, and Jonathan Nakane \\ University of British Columbia \\ ostafichuk@mech.ubc.ca
}

\begin{abstract}
This study tracks wellbeing of a large cohort of first-year engineering students at a large Canadian university over a remotely-delivered academic year. This continues a similar tracking study completed with inperson instruction the previous year. Data were collected through short, weekly surveys rotating through the student cohort. Overall, the results show relatively consistent stressors across the year, driven primarily by academics, and very similar to data from the previous year delivered in person. Wellbeing scores (measured through the Warwick-Edinburgh Mental Wellbeing Scale) declined slightly through the year, and were overall lower than the previous academic year delivered in-person. Considering factors of EDI, female students showed slightly lower wellbeing scores than male students, while international students showed slightly higher scores than Canadian students.
\end{abstract}

Keywords: student wellbeing, student wellness, remote learning, COVID-19, stressors, EDI, gender, international students

\section{INTRODUCTION}

Student wellbeing has become an increasingly important topic in recent years. In 2015, through the Okanagan Charter, universities and colleges around the world have been called to incorporate health promotion values and principles (which encompasses wellbeing) into their mission and vison.[1] Under normal circumstances, students are faced with considerable academic pressure in engineering due to significant course loads, expectations to gain co-op and other work experience, and increasing expectation of participation in extracurricular clubs and design teams. For first year engineering students, these issues are compounded by the additional stress through the transition to the university environment (which is different from what they are used to in many ways, including academically and socially), to potentially living away from home, and to increased independence and selfresponsibility.[2] With the shift to remote teaching due to COVID-19, this has created yet another stressor for students. While this affects all students, first-year students are particularly impacted as they have not yet established the social connections that are known to enhance wellbeing and resilience.[3]

At the University of British Columbia (UBC), we have been examining student wellbeing for several years through a number of studies.[4],[5] In the 2019/20 academic year we began a study looking at student wellbeing on a weekly basis. Through rotating surveys, we assessed student wellbeing using the Warwick Edinburgh Mental Wellbeing Scale (WEMWBS)[6] and we collected ranked data on the most significant stressors impacting students at that time. In this way, we were able to track student wellbeing and the stressors affecting it on a weekby-week basis for one entire academic year. We have continued the same study this year, and are able to consider the impacts of the remote teaching environment on student wellbeing by using the data from the previous year inperson as a baseline.

\subsection{Motivation}

Whereas student wellbeing has been the topic of extensive discussion lately, with much postulating of the likely impacts of remote learning on wellbeing, objective data are required. In addition, stressors can have cumulative effect over time, and the challenges faced by students transitioning to university change week-to-week as they adjust to their new environment, so it is important to understand the evolution of wellbeing as opposed to just a snapshot of wellbeing at a given instant. Lastly, different student populations have different experiences and face different challenges, so it is also important to know how wellbeing differs by student group to best identify needs and direct resources.

\subsection{Literature Review}

The World Health Organization definition of wellbeing has been used within this work, and refers to the state in which an individual "realizes his or her own potential, can cope with the normal stresses of life, can work productively and fruitfully, and is able to make a contribution to her or 
his community."[7] Further, we recognize that wellbeing is a balance between resources available and challenges faced;[8] too many challenges results in feeling overwhelmed, while too few results in feelings of stagnation.

There are many pressures on engineering students which can negatively impact their wellbeing. Competitive engineering programs, and grade pressures during programs, can negatively impact factors related to wellbeing and academic performance.[9],[10] Female engineering students and first year engineering students are also known to have lower mental health scores.[10] In addition, international students have been found to be particularly susceptible to negative wellbeing outcomes, including elevated stress, depression, and anxiety disorders.[11] This is in part attributed to being away from familiar surroundings and home, but also due to new learning environments and potentially a shift from their primary or preferred language. In the remote setting, the impacts for international students are less clear since some factors (being away from home) tend not to apply, while the others may. In addition, online learning is likely to disproportionately impact students with pre-existing feelings of isolation.[12]

On the positive side, factors known to enhance student wellbeing include being active in clubs and sports outside of school, having a social network of peers and others, having healthy relationships with teachers and parents, volunteering, and maintaining a healthy lifestyle.[13] Some early research has revealed social connectedness has changed but not necessarily decreased for university students in the remote learning context.[14]

\subsection{Problem Definition}

There are three related research questions in this work, all considered in the context of first-year engineering in a large Canadian university:

- RQ1: How does student wellbeing change during a remotely-delivered academic year?

- RQ2: Does wellbeing in the remote learning environment differ from wellbeing in the inperson learning environment?

- RQ3: Does student wellbeing in a remote learning environment depend on student gender, nationality, or other dimensions of diversity?

\subsection{Methodology}

To understand how students' perspectives on their wellbeing shift during the academic year, a series of short (under two-minute) optional, anonymous surveys were distributed weekly via email during the 2020-21 academic year. These were the same surveys used in the 2019-20 academic year[5] with the addition of several answer choices related to remote learning and several demographic questions for categorizing responses, as described below.

In both academic years, the first-year cohort was divided into four groups, and the group invited to complete the survey was rotated each week (i.e., each student received a survey invite every four weeks, for a total of three invites per term, six per academic year). This approach was implemented to limit survey fatigue. Participation in the survey was voluntary and no incentive was provided.

This survey asked students to rank topics that were the most challenging to them the prior week, complete the Short Warwick-Edinburgh wellbeing questionnaire,[3] and write a word that described how they felt currently. The choices presented in the activity ranking most challenging topics was drawn from a mapping exercise conducted in the 2018-19 academic year,[4] but was augmented this year with the following stressors related to the remote learning context:

- Adjusting to online learning

- Difficulties or limitations in access to hardware or internet

- Spending too much time online

- Living with family

In addition, following a consultation with the Equity, Diversity, and Inclusion (EDI) committee from our Engineering Undergraduate Society, the following stressors were also included:

- Being treated differently based on my race, ethnicity, gender identity, and/or beliefs

- Feeling disadvantaged or treated differently due to a physical and/or mental disability

Lastly, as in the past, this portion of the survey included an "Other" choice with space for an open textbox response.

The Short Warwick-Edinburgh wellbeing questionnaire was used to assess wellbeing. It consists of seven items and students are asked to indicate the frequency with which each applies using a 5-point scale (none of the time, rarely, some of the time, often, all of the time):

1. I've been feeling optimistic about the future

2. I've been feeling useful

3. I've been feeling relaxed

4. I've been dealing with problems well

5. I've been thinking clearly

6. I've been feeling close to other people

7. I've been able to make up my own mind about things 
To assist with understanding wellness within our program through an EDI lens, several optional demographic questions were added to the end of the survey. The questions were marked optional, and all included a "Prefer not to say" response. These questions explored five main dimensions of diversity:

- Gender identity

- Student status (international or domestic)

- Disability (including mental and physical)

- Racial, ethnic, and/or nationality group(s), including Indigenous and non-Indigenous groups

- Route of entry to program (e.g. direct from high school, transfer, etc.)

\subsection{Significance}

This work adds to the understanding of student wellbeing through detailed, week-by-week tracking in a remote learning setting. Importantly, baseline data exists for the program delivered in-person and in the same weekby-week resolution, allowing direct comparison between remote and in-person learning. In addition, this work adds to the understanding of the factors and impacts on wellbeing particular to different demographic groups in a large first-year engineering cohort at a large, researchintensive Canadian university.

\section{CONTEXT}

The study described in this paper was conducted in the first-year engineering program at UBC. This program has a normal annual intake of between 800 and 1,000 students into a common curriculum, although this year was closer to 1,100 . There is a competitive process to enter a secondyear engineering program (e.g. civil, electrical, mechanical, etc.) which occurs shortly after the end of first year, and is based primarily on first-year GPA, although programs also consider written personal statements from students who rank that program as their first choice.

The first-year curriculum consists primarily of foundational math and science courses, but all students take several engineering courses with strong team focus.

\section{Results}

Results are presented below in terms of the WEMWBS findings and student concerns (for the full cohort and then in terms of key aspects related to EDI), followed by a comparison of the results for the remote learning environment this year to the in-person environment from the previous year.

\subsection{WEMWBS Wellbeing Data (Remote)}

The weekly WEMWBS data (for 2020/21 to date) are shown in Fig. 1. The most notable features include a slight downward trend in the data $(-0.010$ /week, $r=0.100$, when converted to a 1-5 scale), that the "I've been able to make up my own mind" item is consistently the highest rated, and that the "I've been feeling relaxed" item is consistently rated the lowest. Other important observations include that wellbeing shows only minor fluctuations week-by-week; these students had major project deliverables due on weeks $1-5,1-8,1-12$, and $2-5$, with midterm exams mainly clustered from 1-6 to 1-10.

All of the time

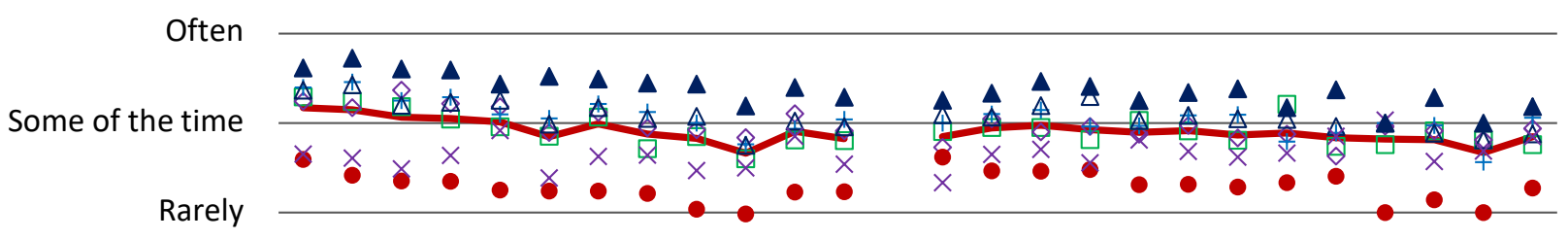

None of the time

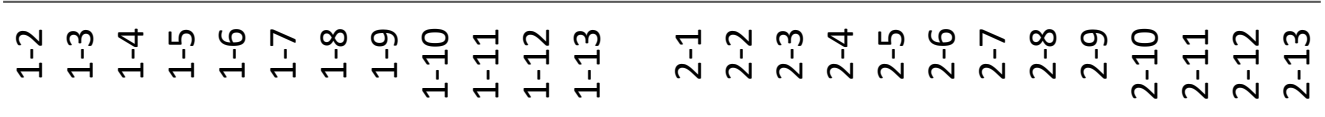

Week

Optimistic about the future

+ Dealing with problems well

\ Make up my own mind
$\diamond$ Feeling useful
$\triangle$ Thinking clearly
-Average

- Feeling relaxed

$\times$ Feeling close to others

Fig. 1. Change in WEMWBS by week

CEEA-ACEG21; Paper 055

UPEI; June 20 - 23, 2021 


\subsection{Student Concerns (Remote)}

The most prevalent student-ranked stressors are shown by week in Fig. 2. As students were asked to rank the items they selected (up to five items maximum), the results shown are with a weighting of 5 points for a student's topranked response, 4 points for second-ranked, and so on. Options with a weighted average of $2 \%$ or less overall are lumped into the "all other" category and include personal relationships $(2.0 \%)$, working with teammates $(1.6 \%)$, being away from family, friends, and/or community $(1.4 \%)$, difficulties or limitations in access to hardware or internet $(0.9 \%)$, living with family $(0.6 \%)$, being treated differently based on race, ethnicity, gender identity, and/or beliefs $(0.5 \%)$, feeling disadvantaged or treated differently due to a physical and/or mental disability $(0.4 \%)$, and an open textbox "other" category (1.4\%).
Of particular note in these data is that roughly $50-60 \%$ of stressors each week come from four factors related to academics: getting high grades (15\%), workload (14\%), getting to one's chosen engineering program (14\%), and passing exams and courses (13\%). (To this last point, entry from the common first year at UBC into second year engineering programs is done competitively with GPA as the primary - and in some cases only-consideration). Importantly, stressors related to remote learning were less significant that academic stressors; "time spent online" $(5 \%)$, "adjusting to online learning" (3\%), and "difficulties or limitations in access to hardware or internet" $(0.9 \%)$ collectively represented less than $10 \%$. Stressors related to maintaining wellbeing, including "maintaining a healthy lifestyle" (9\%), "making friends" (6\%), and "continuing hobbies / activities" (4\%) followed academics as the next most significant broad area of concern.

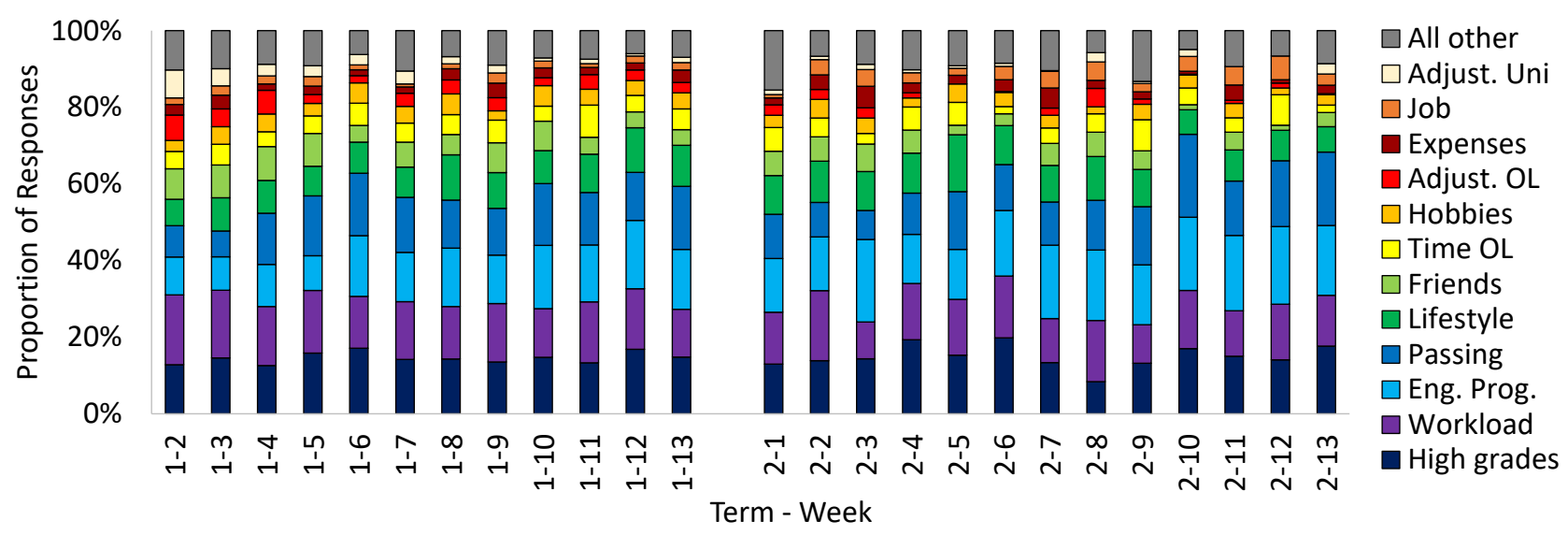

Fig. 2. Most significant student stressors by week

\subsection{EDI Considerations for WEMWBS}

Wellbeing was also considered through the various dimensions of diversity outlined in Section 1.4. In terms of disability, Table 1 summarizes the average WEMWBS score by the type of self-reported disability (responses have been omitted for students who left this question blank or who replied "Prefer not to answer"). The n-values represent the number of survey responses received; since the survey is optional and anonymous and each student is invited to complete the survey at different times over the year, this value is not necessarily representative or proportional to the full population. However, the data do provide some useful insights.

There were no statistically significant differences between the students who did not report a disability and any of the groups of students who did in terms of overall wellbeing. The low numbers of students reporting a disability is one reason for this lack of statistical significance. However, for those students who selfreported a mental disability, they scored lower (with statistical significance) in three of the seven WEMWBS items: "I've been feeling optimistic about the future," "I've been dealing with problems well," and "I've been thinking clearly."

Table 2 presents the average WEMWBS scores for the intersection of gender identity and nationality. The first number in each cell is the average WEMWBS score across all seven items and all weeks, and the second number indicates the number of survey responses for that group. As shown, students from outside Canada tend to report better wellbeing than their Canadian counterparts, and male students tend to report better wellbeing than female students. 
Proceedings 2021 Canadian Engineering Education Association (CEEA-ACEG21) Conference

Table 1: Wellbeing (WEMWBS) by type of disability

\begin{tabular}{|c|c|c|c|c|}
\hline $\begin{array}{l}\text { Self-reported } \\
\text { disability }\end{array}$ & $\mathbf{n}$ & $\begin{array}{l}\text { WEMWBS } \\
\text { Average }\end{array}$ & $\begin{array}{l}\text { p-valued compared } \\
\text { to "none" }\end{array}$ & Comments in comparison to "none" group \\
\hline None & 1340 & 2.97 & - & - \\
\hline Physical & 15 & 3.21 & 0.187 & $\begin{array}{l}\text { Higher in terms of "dealing with problems well" } \\
(3.60 \text { vs } 3.16, p=0.032)\end{array}$ \\
\hline Mental & 49 & 2.74 & 0.068 & 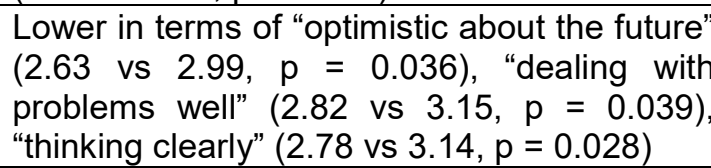 \\
\hline $\begin{array}{l}\text { Physical and } \\
\text { mental }\end{array}$ & 6 & 2.40 & 0.240 & No significant items (1 higher, 6 lower) \\
\hline
\end{tabular}

Table 2: Wellbeing (WEMWBS) by gender and nationality

\begin{tabular}{|r|c|c|c|}
\hline & Canada & $\begin{array}{c}\text { Indigenous } \\
\text { in Canada }\end{array}$ & $\begin{array}{c}\text { Inter- } \\
\text { national }\end{array}$ \\
\hline Female & $\begin{array}{c}2.82 \\
(\mathrm{n}=366)\end{array}$ & $\begin{array}{c}3.36 \\
(\mathrm{n}=2)\end{array}$ & $\begin{array}{c}2.90 \\
(\mathrm{n}=121)\end{array}$ \\
\hline Male & $\begin{array}{c}2.96 \\
(\mathrm{n}=635)\end{array}$ & $\begin{array}{c}2.86 \\
(\mathrm{n}=2)\end{array}$ & $\begin{array}{c}3.05 \\
(\mathrm{n}=299)\end{array}$ \\
\hline $\begin{array}{r}\text { Non- } \\
\text { binary }\end{array}$ & $\begin{array}{c}2.47 \\
(\mathrm{n}=13)\end{array}$ & $\begin{array}{c}- \\
(\mathrm{n}=0)\end{array}$ & $\begin{array}{c}2.71 \\
(\mathrm{n}=5)\end{array}$ \\
\hline
\end{tabular}

The only statistically significant differences between groups in the table is between Canadian female students and male students (both those from Canada, $\mathrm{p}=0.006$, and those international $\mathrm{p}<0.036$ ). Overall, female students had lower WEMWBS scores than male students $(2.85$ compared to 2.99, $\mathrm{p}<0.001$ ), and Canadian students had lower WEMWBS scores than international students $(2.90$ compared to $3.00, \mathrm{p}=0.010$ ). The numbers of students selfidentifying as non-binary or as Indigenous (in Canada) were too low for statistical significance; however, the lower values in the table for non-binary students is cause for concern and suggests ongoing examination is needed.

\subsection{EDI Considerations for Stressors}

The student concerns presented by student group is presented in Fig. 3. No appreciable differences in terms of gender or nationality were noted, with the exception of getting into a second-year engineering program of choice (students who identified as male and international students cited this as a higher concern), and passing courses (student who identified as female and Canadian students cited this as a higher concern).

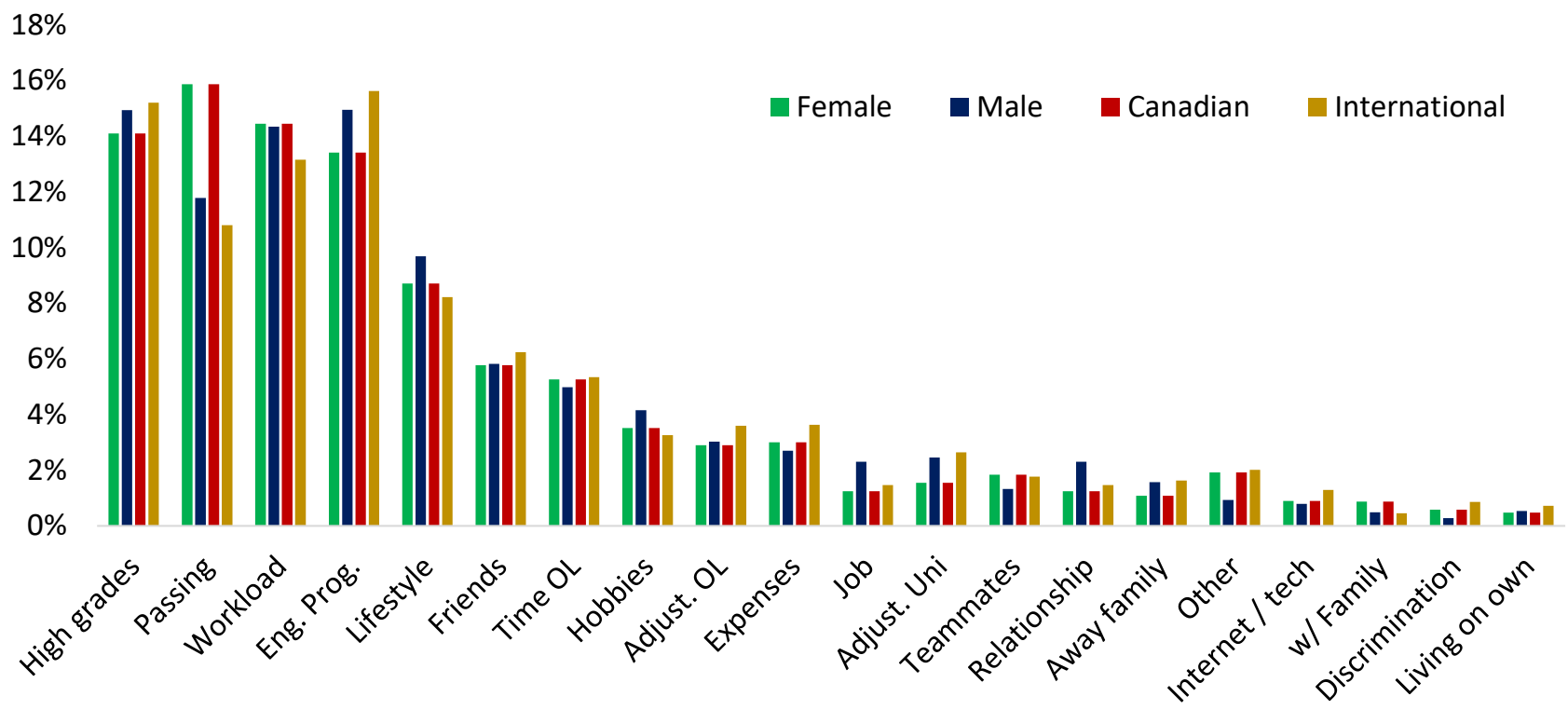

Fig. 3. Most significant student stressors by demographic group 
For students who identified as having a mental disability, a physical disability, or both, the concerns they reported were within $\pm 1 \%$ of the values for the general student population in Fig. 2, with the exception of three items: students reporting a disability were $3 \%$ more likely to identify "feeling disadvantaged or treated differently due to a physical and/or mental disability" as a concern, which makes sense by the nature of the question. They were also $2 \%$ less likely to identify "managing the workload" and $3 \%$ less likely to identify "getting high grades" as concerns. The latter results may be an indication that institutional supports (there is a central Centre for Accessibility that assists with providing accommodations and removing barriers) are effective at helping students with disabilities manage their studies and workload.

\subsection{Comparison to In-person Instruction}

As this same basic survey was used in the prior academic year with in-person instruction (at least until the final few weeks of the second term), it was possible to compare both the WEMWBS data and the data on student concerns for remote and in-person contexts. A comparison of average WEMWBS item scores for the in-person academic year $(2019 / 20)$ and the remote academic year $(2020 / 21)$ are shown in Fig. 4, with 95\% confidence intervals indicated. In both modes of delivery, consistent with the observation from Fig. 1, "I've been feeling relaxed" received the lowest score and "I've been able to make up my own mind" received the highest. More generally, the WEMWBS results for the remote delivery are lower than the corresponding item with in-person delivery, but typically not to a significant level; however, a marked decrease in the "I've been feeling close to other people" item stands out.

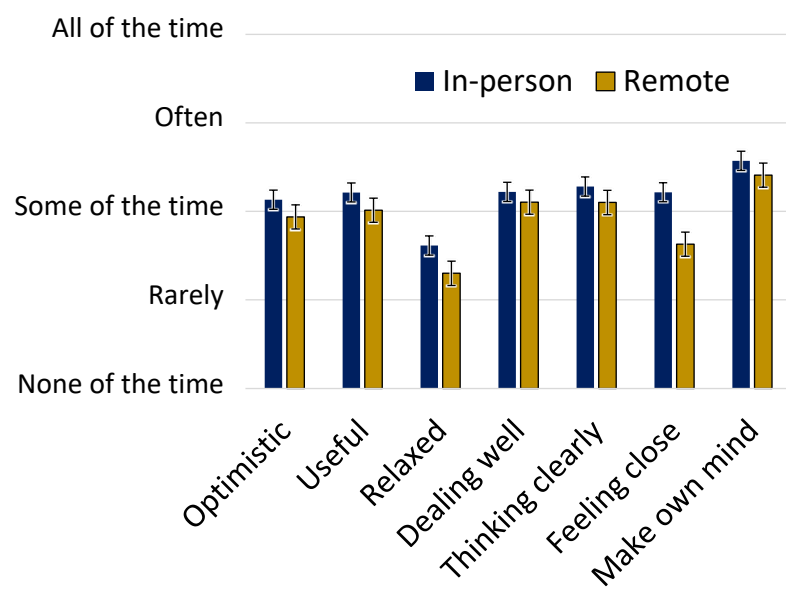

Fig. 4. Comparison of WEMWBS items by year

A comparison of the changes in WEMWBS scores over the academic year for both delivery modes is shown Fig. 5. To simplify the chart, only the average data, the highestrated item ("I feel I am able to make up my own mind"), and the lowest-rated item ("I feel relaxed") are shown for each year. The trends between the two years are similar with two key differences: WEMWBS scores are slightly lower in the remote setting (as noted already), and there is slightly less variability week-to-week with the remote data. (Note: the only data collected in Week 1 in either term was for 2020/21 in Term 2.)

All of the time

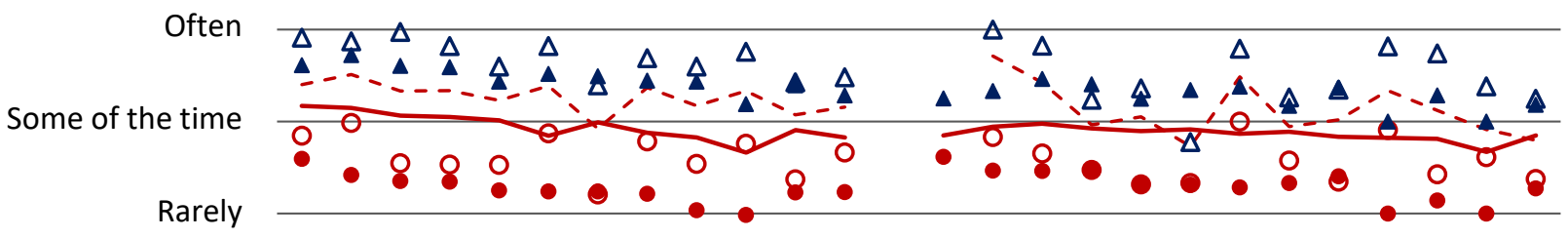

None of the time

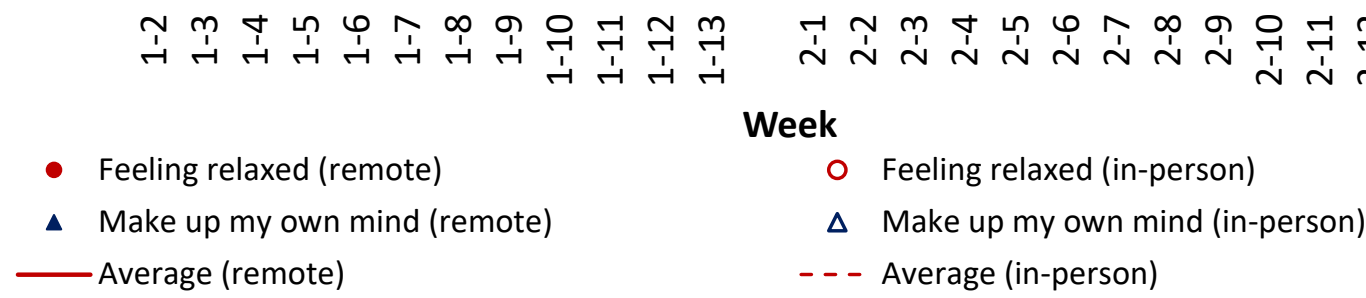

Fig. 5. Comparison WEMWBS trends, 2019/20 to 2020/21 
In Fig. 6 the average responses across all surveys is shown for student concerns by category for both delivery modes. Note that the in 2020/21 (remote) survey, "getting high grades" and "passing" were two separate items while they appeared as a single item in the 2019/20 (in-person) survey; for 2020/21, they have been combined (summed) in the data shown in the chart. Also note that several new items were added to the survey in $2020 / 21$ as noted in Section 1.4 (and marked with a "*” in the figure). The trends between the two years are similar, with the two single largest differences being time spent online as a new concern this year $(5 \%)$, offset by an equal reduction in concern to get into a second-year engineering program of choice.

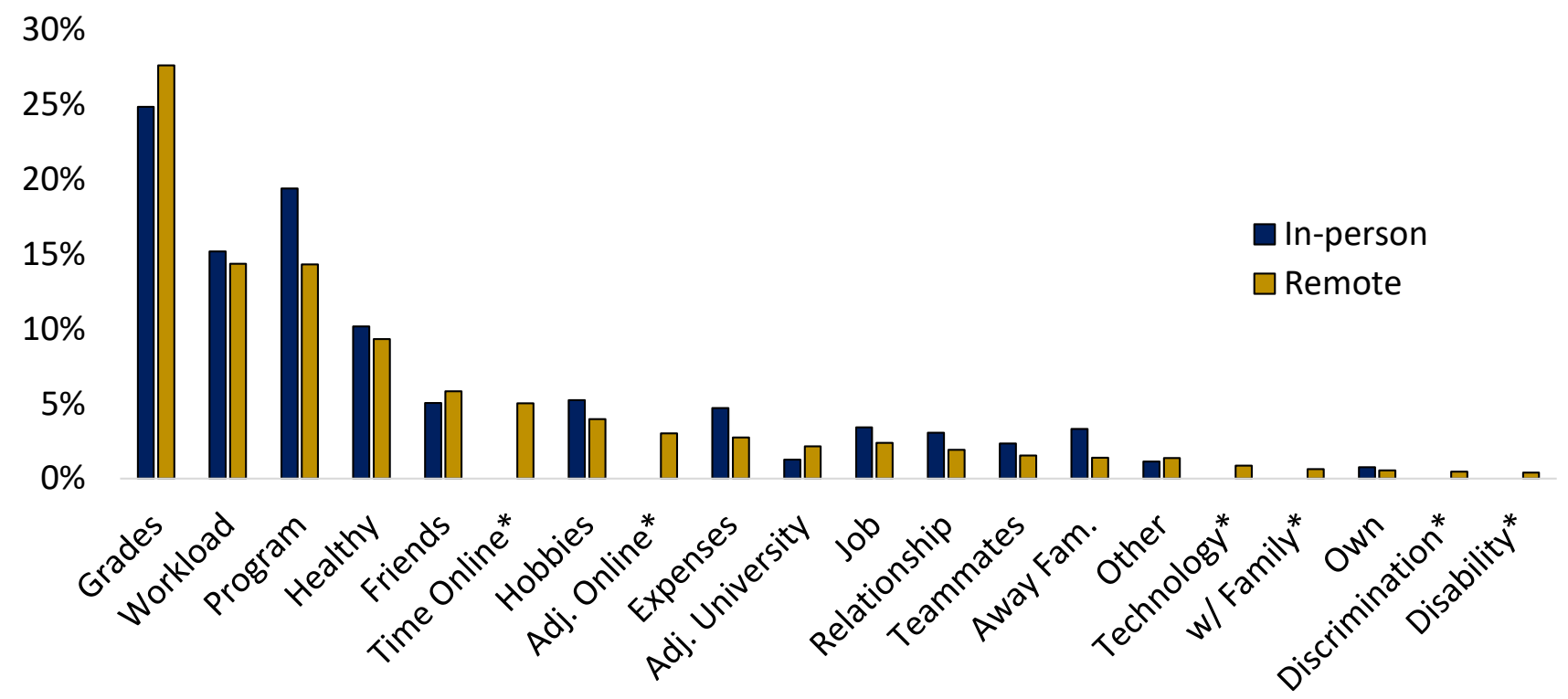

Fig. 6. Comparison of most significant stressors, 2019/20 to 2020/21

\section{DISCUSSION AND CONCLUSIONS}

To our first research question, our results suggest relatively steady student wellbeing during a remotelydelivered academic year, with only a slight downward trend in WEMWBS wellbeing scores. Limited change in student concerns from week to week was noted, with academic concerns (workload, getting high grades, passing, and entering a second-year program of choice) dominating.

Considering our second research question, our results suggest the change to remote learning has had a slight but measurable negative impact on student wellbeing. The WEMWBS data shows similar patterns to that taken from an academic year delivered in person, with similar rank ordering of items in the scale other than the "I've been feeling close to other people" item, which dropped. The ranking of most significant stressors and concerns for students are almost unchanged between remote and inperson instruction in our program; concerns unique to remote learning were small in comparison.
Differences related to EDI dimensions were noted. Consistent with others,[10] we observed wellbeing scores for female students lower than for male students. Unlike others,[11] we found international students had slightly better wellbeing scores than Canadian students, but not to the point of statistical significance. This suggests some of the challenges and stressors faced by international students may be at least partially addressed in the remote learning environment. Lastly, we did not observe statistically significant differences in overall wellbeing in the remote learning environment for students self-reporting a disability, although this appears to be primarily be due to the small sample size.

Taken together, the results suggest remote learning in our context is having slight negative impact on student wellbeing, and that wellbeing differs across underrepresented groups. Academics appear to be a primary stressor for all student groups. The results show a clear need for ongoing efforts to improve student wellbeing to continue, especially through addressing academicrelated stress and by supporting underrepresented students. 


\section{References}

[1] Okanagan Charter: An International Charter for Health Promoting Universities and Colleges, 2015.

[2] S. Fisher, and B. Hood, "The stress of the transition to university: a longitudinal study of psychological disturbance, absent-mindedness and vulnerability to homesickness," J Psychol., vol. 78 (pt 4), pp. 425-441, 1987.

[3] M.M. Awang, F.M. Kutty, and A.R. Ahmad, "Perceived Social Support and Well Being: First-Year Student Experience in University" International Education Studies, vol 7, no 13, 2014, pp. 261-70.

[4] Q.A. Golsteyn, and D. Nino, "An Analysis on the State of Wellness of Engineering Undergraduate Students," in Proc. CEEA-ACEG 2018, Vancouver, BC; 3-6 June, 4 pp., 2018.

[5] Q.A. Golsteyn, and P.M. Ostafichuk, "Assessing and Tracking the Factors Influencing Student Wellbeing in First Year Engineering," Proc. of 2020 CEEA-ACEG Conference, Montreal, QC (virtual), 18-21 June, 7 pp., 2020.

[6] S. L. Stewart-Brown, A. Tennant, R. Tennant, S. Platt, J. Parkinson, and S. Weich, "Internal construct validity of the Warwick-Edinburgh Mental Well-being Scale (WEMWBS): a Rasch analysis using data from the Scottish Health Education Population Survey," Health and Quality of Life Outcomes, vol. 7, no. 15, 2009.

[7] "Mental health: a state of well-being," WHO, 2014. [Online]. Available: http://origin.who.int/features/ factfiles/mental_health/end/.
[8] R. Dodge, A.P. Daly, J.L. Huyton, and L. Sanders, "The challenge of defining wellbeing," International Journal of Wellbeing, vol. 2, no. 3, pp. 222-235, 2012.

[9] A.G. d'Entremont, J.C. Abello, and E. Sharda, "Being a Cstudent is the new normal: a literature review on grades, selfworth, and mental wellbeing," Proc. 2018 CEEA-ACEG, Vancouver, BC, 2018, pp. 6.

[10] M. Deziel, D. Olawo, L. Truchon and L. Golab, “Analyzing the Mental Health of Engineering Students using Classification and Regression." Educational Data Mining, 2013.

[11] C.J. Yeh and M. Inose, 'International students' reported English fluency, social support satisfaction, and social connectedness as predictors of acculturative stress," Counselling Psychology Quarterly, 16(1), 15-28, 2003. doi.org/10.1080/0951507031000114058

[12] Valkenburg, P.M. and Peter, J. (2007), Online Communication and Adolescent Well-Being: Testing the Stimulation Versus the Displacement Hypothesis. Journal of Computer-Mediated Communication, 12: 1169-1182. https://doi.org/10.1111/j.1083-6101.2007.00368.x

[13] OECD, “Good vibrations: Students' well-being”, Trends Shaping Education Spotlights, No. 14, OECD Publishing, Paris, 2018, https://doi.org/10.1787/ dcef822d-en.

[14] D. Folk, K. Okabe-Miyamoto, E. Dunn, and S. Lyubomirsky, "Did Social Connection Decline During the First Wave of COVID-19?: The Role of Extraversion." Collabra: Psychology 1 January 2020; 6 (1): 37. doi: https://doi.org/10.1525/ collabra.365 